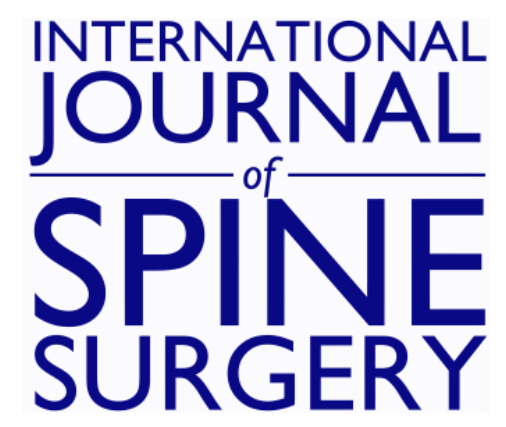

\title{
Early Radiographic and Clinical Outcomes Study Evaluating an Integrated Screw and Interbody Spacer for One- and Two-Level ACDF
}

Paul D. Lane, Jacob L. Cox, Roger B. Gaskins III, Brandon G. Santoni, James B. Billys and Antonio E. Castellvi

Int J Spine Surg 2015, 9 ()

doi: https://doi.org/10.14444/2039

http://ijssurgery.com/content/9/39

This information is current as of April 26, 2023.

Email Alerts Receive free email-alerts when new articles cite this article. Sign up at:

http://ijssurgery.com/alerts

The International Journal of Sping Surgerbhttp://ijssurgery.com/ by guest on April 26, 2 2397 Waterbury Circle, Suite 1,

Aurora, IL 60504, Phone: +1-630-375-1432

(C) 2015 ISASS. All Rights Reserved. 


\section{Early Radiographic and Clinical Outcomes Study Evaluating an Integrated Screw and Interbody Spacer for One- and Two-Level ACDF}

Paul D. Lane, MD, ${ }^{1}$ Jacob L. Cox, MD, ${ }^{2}$ Roger B. Gaskins III, MD, 2 Brandon G. Santoni, PhD, ${ }^{3}$ James B. Billys, MD, ${ }^{1}$ Antonio E. Castellvi, MD 1

${ }_{1}^{1}$ Florida Orthopaedic Institute, Tampa, FL, ${ }^{2}$ University of South Florida, Department of Orthopaedics and Sports Medicine, Tampa, FL, ${ }^{3}$ Foundation for Orthopaedic Research and Education, Tampa, FL

\section{Abstract}

Background

Multiple techniques and implants can be used in ACDF, the newest of which are integrated cage and screw constructs. These devices may be beneficial over anterior plate constructs due to a negligible anterior profile that may reduce dysphagia. The goal of this study is to review the early radiographical and clinical results associated with a low profile integrated intervertebral cage in one- and two-level anterior column fusions.

\section{Methods}

Fusion rates, incidence of hardware failure and deformity correction were assessed through 1 year. Patientreported scores, including VAS for neck pain, and improvements in axial neck pain and neurologic deficit from the preoperative baseline were quantified at 3, 6 and 12 months post-operatively. The incidence of dysphagia was recorded.

Results

Lordosis and disc space height at the operated levels increased an average of $4.5^{\circ}$ and $3.3 \mathrm{~mm}$ after device placement $(\mathrm{p}<0.001)$. Sagittal plane correction was maintained at 1 year. VAS improved from an average of 5.1 preoperatively to 3.1 immediately postoperatively and was maintained at 12 months. At 3 months, patient-reported improvements in axial neck pain and neurologic deficit were $85 \%$ and $93 \%$, respectively. Reported improvements were sustained for both parameters at 12 months (77\% and 86\%, respectively). Fusion was noted in $93 \%$ of the operated levels. There were two documented cases of dysphagia that lasted more than 5 weeks, both following two level ACDFs with the test device (3.5\% rate of chronic dysphagia).

\section{Conclusions}

The low profile integrated device improved lordosis at the operated level that was maintained at 1 year. Fusion rates with the new device are consistent with ACDF using anterior plating. In combination with improvements in pain and a minimal rate of dysphagia, study findings support the use of integrated interbody spacers for use in oneand two-level ACDF procedures.

Level of Evidence

Level IV, Case Series.

KEYWORDS: ANTERIOR CERVICAL DISCECTOMY AND FUSION, INTEGRATED INTERBODY SPACER, RADIOGRAPHIC FUSION, CLINICAL OUTCOMES VOLUME 9 ARTICLE 39 - BIOMECHANICS SPECIAL ISSUE DOI: 10.14444/2039

\section{Introduction}

Cervical degenerative disc disease is a very common problem. Related neurological symptoms include radiculopathy and myelopathy, which can arise from trauma, activities that increase stress on the cervical spine and the normal process of aging. Symptoms are routinely initially treated with conservative measures ranging from physical therapy, chiropractic treatment, oral pain or anti-inflammatory medications, and epidural steroid injection. When these less invasive measures fail to satisfactorily relieve symptoms, surgical intervention is warranted. Surgical options include cervical total disc replacement, posterior 
foraminotomy, anterior partial discectomy and foraminotomy, anterior cervical discectomy and fusion (ACDF), and posterior decompression with or without fusion.

Clinical literature indicates single-level ACDF fusion rates ranging from $83 \%-97 \%$ using autografts and 82\%-94\% using allografts with concomitant relief of arm and neck pain. ${ }^{1,2}$ The technique for ACDF was simultaneously and independently reported by Cloward as well as Smith and Robinson in 1958. Since that time the technique has evolved and includes several options for implants including disc spacers made of autograft or allograft bone, porous metal, polyether ether ketone (PEEK) and anterior plates and screws. The addition of anterior plates and screws was first reported by Orozio in 1970.

Benefits of anterior plates and screws include improved biomechanical fixation, higher fusion rates and decreased need for cervical collars after surgery. ${ }^{1,2}$ Resultantly, the use of anterior plates and screws in ACDF is common practice today. Potential drawbacks of plating include the anterior profile of the plate, which may be related to chronic dysphagia after surgery. ${ }^{3-5}$ There is also the added risk of plate migration that may result in catastrophic esophageal perforation. ${ }^{6}$ Additionally, studies have reported increased adjacent level ossification when the plate is within $5 \mathrm{~mm}$ of the disc above or below the operative level. ${ }^{7}$ Park et al. reported adjacent level ossification in $67 \%$ of the levels above the surgical level when the plate was $<5 \mathrm{~mm}$ from the superior disc and only $24 \%$ when $>5 \mathrm{~mm}$ away. In the level below, ossification was seen in $45 \%$ versus $5 \%$ when the plate was within $5 \mathrm{~mm}$ or farther than $5 \mathrm{~mm}$, respectively. ${ }^{7}$

Recently new implants have been designed for ACDF to address some of the issues with anterior plates and screws. These implants are commonly described as zero or no profile integrated cage and screw implants. They sit just dorsal to the anterior cortex of the cervical vertebral body, completely contained within the intervertebral disc space. Potential benefits of this implant include decreased dysphagia, lower risk of migration, and lower incidence of adjacent segment degeneration.
As clinical data regarding the utility of these devices are sparse in the literature, the purpose of this study was to evaluate the early (12 months) clinical and radiographic results of ACDF performed with a zero anterior profile cage and integrated three screw implant.

\section{Materials \& Methods}

A retrospective review of all one- and two-level ACDFs was performed from 2010 to 2013 on all patients who received the test implant. All procedures were performed by two fellowship-trained spine surgeons at a single institution using a standard Smith Robinson anterior approach to the cervical spine. All patients had at least 12 months follow-up. Inclusion criteria for the study were cervical pathology suitable for treatment with $\mathrm{ACDF}$, age greater than 18 years old, and 1-2 diseased cervical levels. Exclusion criteria included need for posterior fixation, greater than 2 affected levels, and history of dysphagia prior to surgery. Fifty-seven patients (36 females; 21 males) with 73 operated levels met our inclusion criteria and were followed clinically and radiographically for 12 months.

The test implant was a PEEK interbody cage with 6 degrees of lordosis and three integrated screws (STALIF C, Centinel Spine, West Chester, PA). Implants were available in two styles, one with a domed superior surface, and one with a flat superior surface. Each implant had three screws. The midline screw is designed to be directed superiorly, and the inferior screws are meant to be directed inferiorly and converge in the midline. Implant sizes ranged from 5.5-9.5mm in height in tapered versions, with the domed versions adding $1.44 \mathrm{~mm}$ of height at the dome peak. The PEEK cage has an open void in the center that was filled with bone graft and/or substitute. Osteocel (Nuvasive, San Diego, CA) and local autograft bone were used in 22 patients while $27 \mathrm{pa}$ tients received Grafton DBM Gel (BioHorizons, Birmingham, AL) and allograft cancellous bone chips. DBX putty (DepuySynthes, Westchester, PA) and allograft cancellous bone chips were used in 5 patients. Local autograft and allograft cancellous bone chips were used in 3 patients. 
Change in lordosis and intervertebral disc height at the operated levels was evaluated immediately postoperatively and at 1 year (lordosis only). Fusion status, VAS for neck pain, NDI, patient-reported improvement in neck pain and neurologic symptoms, and incidence of dysphagia were evaluated at 3 months, 6 months and 12 months postoperatively.

Radiologic outcomes were measured using plain lateral radiographs of the cervical spine taken at each postoperative visit from immediately after surgery until 12 months. Radiographs were taken using a standardized protocol in which the radiology technician instructed the patient to stand perfectly straight and as close to the detector as possible. The only exceptions to plain radiographic analysis were the cases where CT was available to determine fusion status. Disc height was measured on preoperative and immediate postoperative radiographs and determined by measuring the distance from the posterior inferior aspect of the superior vertebral body to the posterior superior corner of the inferior vertebral body. This location was used versus the anterior disc height as it was felt this would give a better measurement of the increase in vertical neural foramen height and therefore indirect decompression of the foramen. Radiographic images were calibrated for disc height measurement using a calibration scale placed in the x-ray field at the level of the detector. Lordosis was determined at the operative level by measuring the angle between the superior endplate of the superior vertebral body and the inferior endplate of the inferior vertebral body. The combination of disc height and lordosis at the operative level was additionally used to determine the incidence of implant subsidence after surgery. Fusion status was determined one of two ways. If a CT of the cervical spine was available that showed a solid fusion, this study was used. If no CT was available, flexion/extension xrays were used to monitor for motion at the operative level (Figure 1). A level was deemed to be fused if a difference of $2^{\circ}$ or less of intervertebral motion at the operated level was measured between the full flexion and full extension radiographs. This motion threshold has been utilized in prior literature assessing fusion after ACDF in the cervical spine. ${ }^{8-11}$ All imaging studies were evaluated by a board certified musculoskeletal radiologist blinded to the purpose of the study.
Patient-reported outcomes included improvement in axial neck and arm pain, and the presence or absence of dysphagia. VAS and NDI score were obtained at each clinical visit. Change in disc height from the pre-operative baseline to the immediate postoperative was compared with a paired t-test (SPSS, v22, IMB, Armonk, NY). Change in lordosis at the operated level over 12 months as well as improvements in clinical measures were determined with a repeated measures analysis of variance (RM-ANOVA) with Bonferroni correction. Significance was set at $\alpha=0.05$.

\section{Results}

Of the 73 operated levels, 41 were single-level ACDFs and 16 were two-level ACDFs (Figure 2). The majority of single-level ACDFs were performed at the C5-C6 level (Table 1). Of the 16 two-level $\mathrm{ACDF}$, the most frequent was implantation at C5-C6 and C6-C7. Operative time was 110 minutes $( \pm 42)$, and blood loss was $89 \mathrm{cc}( \pm 45)$. The most frequent implant used was the tapered $6.5 \mathrm{~mm}$ interbody cage (47\% of all cases) (Table 2 ). Domed interbody cages were used in two operated $\mathrm{C} 5 / \mathrm{C} 6$ levels $(3 \%)$ in two patients due to endplate concavity. The most commonly used screws were $15 \mathrm{~mm}$ (57\%) and $16 \mathrm{~mm}(35 \%)$ in length. We documented one hardware failure in our patient cohort, manifested as breakage of a single screw, which did not require any further treatment. The patient was asymptomatic, and the radiographic correction obtained from surgery was

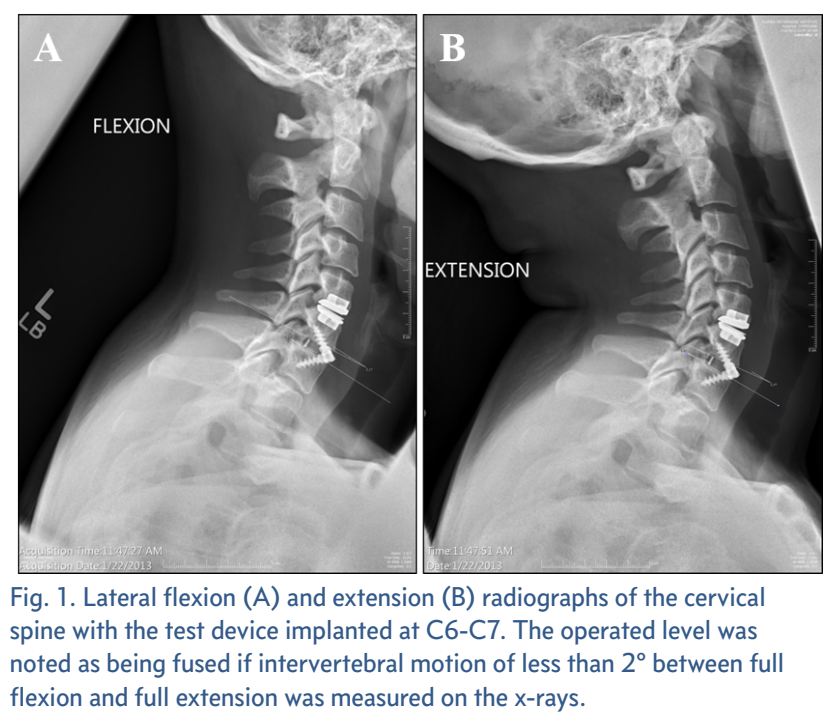


maintained at the last visit.

Forty-two patients (age 29-73) with 57 out of a total of 73 operated levels had appropriate imaging available to evaluate fusion status. Of the 57 operated levels, 54 were found to be solidly fused resulting in a fusion rate of $93 \%$ (Table 3 ). The 4 operated levels that did not fuse were in two patients that underwent two-level ACDFs. Lordosis was significantly improved immediately postoperatively compared to baseline films an average of 4.5 degrees $(\mathrm{p}<0.001)$ (Table 4). Lordosis was maintained at one year postoperatively at 4.5 degrees. Intervertebral disc height

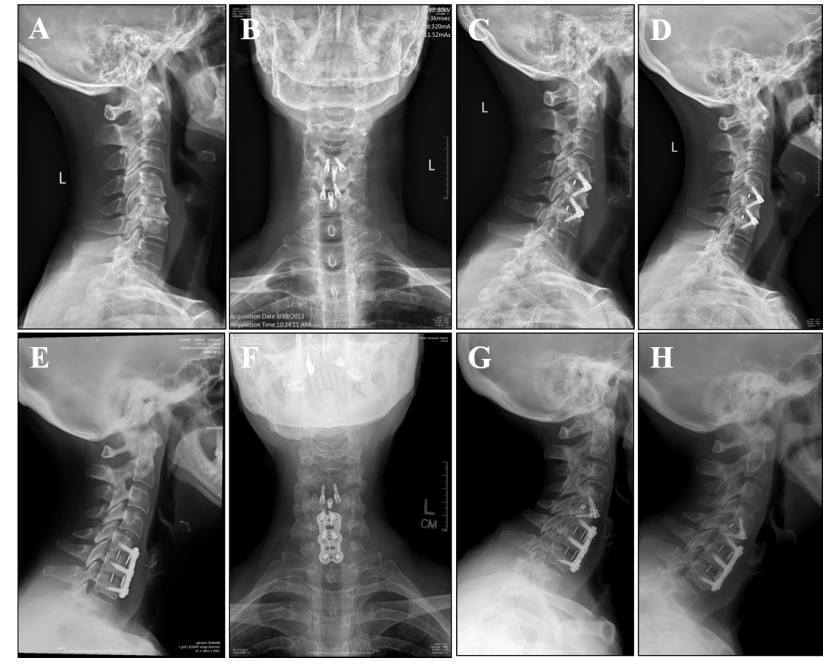

Fig. 2. Pre-operative radiographs of patients undergoing two-level (A) and one-level (E) ACDF with the test device. Immediate postoperative AP and lateral images $(B, C)$ and $(F, G)$ and lateral radiograph of the two-level $(D)$ and one-level $(\mathrm{H})$ fusions taken one year after the surgery.

Table 1. Frequency of 1-Level ACDFs with the test device.

\begin{tabular}{|l|r|r|r|r|r|}
\hline & C3-4 & C4-5 & C5-6 & C6-7 & C7-T1 \\
\hline 1-Level ACDFs & 5 & 8 & 11 & 16 & 1 \\
\hline $\mathrm{n}=41$ & $(12.1 \%)$ & $(19.5 \%)$ & $(26.8 \%)$ & $(39.0 \%)$ & $(2.4 \%)$ \\
\hline
\end{tabular}

Table 2. Summary of interbody device sizes implanted.

\begin{tabular}{|l|r|r|}
\hline Cage Size/Type & \# of Levels & $\%$ \\
\hline $5.5 \mathrm{~mm}$ Tapered & 13 & $17.8 \%$ \\
\hline $6.5 \mathrm{~mm}$ Tapered & 34 & $46.6 \%$ \\
\hline $6.5 \mathrm{~mm}$ Domed & 2 & $2.7 \%$ \\
\hline $7.5 \mathrm{~mm}$ Tapered & 21 & $36.8 \%$ \\
\hline $8.5 \mathrm{~mm}$ Tapered & 2 & $3.5 \%$ \\
\hline $9.5 \mathrm{~mm}$ Tapered & 1 & $1.8 \%$ \\
\hline
\end{tabular}

also significantly increased on average $3.3 \mathrm{~mm}$ from $4.3 \pm 1.4 \mathrm{~mm}$ pre-operatively to an average of $7.6 \pm$ $1.2 \mathrm{~mm}$ after surgery $(\mathrm{p}<0.001)$. No evidence of cage subsidence was noted radiographically.

Thirty patients had complete outcomes data at the one year time point. VAS for neck pain improved from an average of 5.1 (range 2-10) preoperatively to 3.1 (range 0-9) immediately postoperatively $(\mathrm{p}<0.001)$ and was maintained at 3.3 (range $0-9)$ at 12 months. NDI decreased from 39.8 (range 16-94) at the pre-operative baseline to 28.0 (range 12-82) $(\mathrm{p}=0.053)$ at 3 months and was maintained at 25.0 (range 10-82) at 1 year. At 3 months, patient-reported improvements in axial neck pain and neurologic

\begin{tabular}{|c|c|c|c|c|c|c|}
\hline $\begin{array}{l}\text { Graft } \\
\text { Used }\end{array}$ & $\begin{array}{r}\mathrm{n} \text { (cases } \\
\text { with radi- } \\
\text { ographic } \\
\text { follow-up) }\end{array}$ & $\begin{array}{r}\text { \# of } \\
\text { levels }\end{array}$ & $\begin{array}{r}\text { 1-level } \\
\text { procedures } \\
\text { (\# fused) }\end{array}$ & $\begin{array}{r}\text { 2-level } \\
\text { procedures } \\
\text { (\# fused) }\end{array}$ & $\begin{array}{r}\text { \# lev- } \\
\text { els } \\
\text { fused }\end{array}$ & $\begin{array}{r}\% \text { fu- } \\
\text { sion }\end{array}$ \\
\hline $\begin{array}{l}\text { Osteocel } \\
+ \text { auto- } \\
\text { graft }\end{array}$ & 15 & 21 & $9(9 / 9)$ & $6(12 / 12)$ & 21 & $100 \%$ \\
\hline $\begin{array}{l}\text { Grafton } \\
\text { DBM + } \\
\text { allograft }\end{array}$ & 22 & 30 & $14(14 / 14)$ & $8(14 / 16)$ & 28 & $93 \%$ \\
\hline $\begin{array}{l}\text { Allograft } \\
+ \text { auto- } \\
\text { graft } \\
\text { chips }\end{array}$ & 2 & 2 & $2(2 / 2)$ & None & 2 & $100 \%$ \\
\hline $\begin{array}{l}\text { DBX } \\
\text { Putty }+ \\
\text { allograft } \\
\& \text { auto- } \\
\text { graft } \\
\text { chips }\end{array}$ & 3 & 4 & $2(2 / 2)$ & $1(0 / 2)$ & 2 & $50 \%$ \\
\hline Total & 42 & 57 & $\begin{array}{l}27(27 \\
\text { levels) }\end{array}$ & $\begin{array}{l}15 \text { (30 } \\
\text { levels) }\end{array}$ & 53 & $93 \%$ \\
\hline
\end{tabular}

\begin{tabular}{|c|c|c|c|c|}
\hline Level & $\begin{array}{r}\text { \# of Op- } \\
\text { erated } \\
\text { Levels }\end{array}$ & $\begin{array}{r}\text { Pre-Operative Lor- } \\
\text { dotic Angle (de- } \\
\text { grees) (mean }+/- \\
\text { SD) }\end{array}$ & $\begin{array}{r}\text { Post-Operative } \\
\text { Lordotic Angle } \\
\text { (degrees) (mean }+/- \\
\text { SD) }\end{array}$ & $\begin{array}{r}\text { Average In- } \\
\text { crease Per } \\
\text { Level (de- } \\
\text { grees) }\end{array}$ \\
\hline C3-4 & 10 & $3.6 \pm 3.0$ & $8.2 \pm 2.5$ & 4.6 \\
\hline $\mathrm{C} 4-5$ & 13 & $1.7 \pm 1.9$ & $6.0 \pm 2.0$ & 4.3 \\
\hline $\mathrm{C} 5-6$ & 22 & $0.9 \pm 0.8$ & $5.8 \pm 1.4$ & 4.9 \\
\hline C6-7 & 26 & $1.0 \pm 1.0$ & $5.2 \pm 1.4$ & 4.2 \\
\hline C7-T1 & 2 & $0.3 \pm 0.4$ & $4.8 \pm 1.6$ & 4.5 \\
\hline $\begin{array}{l}\text { All } \\
\text { Levels }\end{array}$ & 73 & $1.5 \pm 1.8$ & $6.0 \pm 1.9$ & 4.5 \\
\hline
\end{tabular}


deficit were $85 \%$ and $93 \%$, respectively. Reported improvements were sustained for both parameters at 12 months (77\% and $86 \%$, respectively). Twenty patients did not have complete clinical outcome scores at 1 year, representing a 35\% lost to follow-up rate.

Fourteen patients $(25 \%)$ reported dysphagia at some point postoperatively. Ten cases resolved in 2 weeks, and 2 cases resolved in 5 weeks. The remaining 2 patients continued to have some dysphagia at the one year mark, both of which were 2-level ACDFs. The rate of chronic dysphagia was $3.5 \%$ in our patient cohort surgically treated with the integrated interbody devices.

\section{Discussion}

Stand-alone cage and screw implants for ACDF are a relatively new class of devices used for surgical treatment of cervical spine pathology. Stein et al. ${ }^{12}$ evaluated the same test implant used in our clinical study against locked anterior plate fixation at a single level in human cadaveric spines and concluded that the integrated screw and cage implant conferred nearly equivalent acute biomechanical stability to traditional plating (within $1^{\circ}$ of motion in all loading modes). Similar biomechanical findings were recently reported by the same group over two contiguous cervical spine levels. ${ }^{13}$ These and other similar studies ${ }^{14}$ provide biomechanical evidence supporting the use of integrated spacers as an alternative to rigid anterior plating for ACDF procedures.

Studies on the short- and medium-term clinical efficacy associated with the use of these devices are beginning to emerge due to their relatively recent introduction in the cervical spine implant market. Barbagallo et al. ${ }^{15}$ reported on 85 patients with 4 year follow up using a zero profile stand-alone cage and screw implant. SF-36 and NDI showed a statistically significant improvement $(p<0.01)$ and mean arm pain VAS score decreased from 79 to 41 . X-rays and CT demonstrated, respectively, a $94.5 \%$ and a $92 \%$ fusion rate. Three patients complained of moderate and two of mild transient dysphagia (15.5\%). No device-related complications occurred and no fractures were reported. They found the zero profile device to be safe and effective, even on multilevel cases.
This series has the longest follow up to date. ${ }^{15}$

Hofstetter and coworkers ${ }^{16}$ compared the incidence of dysphagia in ACDF with an anterior plate versus a stand-alone cage and screw construct. They looked at 70 patients total, 35 with an anterior plate and 35 with a zero profile stand-alone cage and screw implant. Radiographs showed increased prevertebral swelling in the anterior plate group out to six months. There were also 7 patients in the anterior plate group that complained of dysphagia compared to only one in the zero profile group. ${ }^{16}$ In the current study, we only had 2 patients with dysphagia that lasted more than 5 weeks, and both patients were two level ACDFs. This gave us a chronic dysphagia rate of $3.5 \%$, which compares favorably with dysphagia rates in other studies evaluating these new interbody devices. ${ }^{17-22}$ Yue et al. ${ }^{22}$ reported a chronic dysphagia rate of approximately $35 \%$ in patients who underwent ACDF using an anterior plate with a 5-11 year follow up. Riley et al. ${ }^{19}$ reported a dysphagia rate of approximately $11 \%$ and $24 \%$ at 2 years after surgery in oneand two-level plated constructs, respectively. Similar to our findings, Li et al. ${ }^{17}$ demonstrated a trend towards decreased incidence of dysphagia with a zero profile implant versus an anterior plate. They looked at 46 patient's prospectively, 23 in the zero profile group and 23 in the anterior plate group. At all time points, the control group with the anterior plate reported more dysphagia than the test group with the zero-profile implant. At one year postoperatively, 4 patients in the control group reported mild dysphagia compared to no reported dysphagia in the test group.

We noted only a single instance of hardware failure in our study cohort, which manifested as breakage of a single screw. The patient was asymptomatic at the index level, no further treatment was deemed necessary and the operated level went on to radiographic fusion. Migration of hardware is of particular concern with anterior cervical plates as the consequences of prominent anterior hardware can be severe, and range from dysphagia to esophageal perforation as described in other studies. ${ }^{3-5,6}$ Further, at one year we identified no instances of subsidence of the integrated interbody spacer. Our finding is in agreement with those of Scholz et al. ${ }^{23}$ who also reported early radiographic outcomes with a similar 
test device. Certainly, longer follow up is necessary to confirm our findings at 12 months.

Our fusion rate in this study was $93 \%$, consistent with published ACDF fusion rates. Kaiser et al. ${ }^{1}$ reported single- and two-level ACDF fusion rates with an anterior plate and cortical allograft of $96 \%$ and $91 \%$, respectively. Song et al. ${ }^{24}$ compared the fusion rates of $\mathrm{ACDF}$ with anterior plate and cage versus cage only. They found a fusion rate of $97.5 \%$ in the plated group versus $78.9 \%$ in the cage only group. Again, our fusion rate in this study was similar to the rates found for constructs using anterior plates. Barbagallo et al. ${ }^{15}$ tested a similar zero profile cage and screw implant and reported a $92 \%$ fusion rate on CT.

Our patient satisfaction rates with symptom improvement and improvement in VAS scores were also similar to established success rates in ACDF of approximately $90 \%$ or better. ${ }^{7,16}$ Patients reported improvements in neck and arm pain of $77 \%$ and $86 \%$, respectively, one year out from surgery. Zero profile stand-alone cage and screw implants perform comparably to cage and anterior plate constructs in terms of fusion and patient rated factors such as symptom relief. $^{15,17}$

Our study has several limitations. Firstly, the radiographic measurements were performed by a single observer and thus we have no measure of inter-rater reliability. However, prior work by our group in a study of similar scope indicates that such radiographic measurements can be performed with a high degree of correlation between observers (intraclass correlation $(\mathrm{ICC})=0.986) .{ }^{25}$ Secondly, we acknowledge the potential for linear distance measurement error (i.e. disc height). We attempted to minimize this error by utilizing a standard imaging protocol, but, nonetheless, we acknowledge that slight deviations in patient positioning as well as parallax may affect the measurements. Thirdly, this was a retrospective study and we acknowledge a moderate lost to follow up rate with 20 patients lacking complete clinical outcomes data at 1 year post-operatively and only 42 patients having radiographical data to assess fusion. In an attempt to minimize our lost to follow-up rate, we made multiple attempts (x3) over a three month period to contact all patients with incomplete data.
Finally, this is a relatively small patient cohort that demonstrates similar fusion rates and clinical improvements to patients historically treated with rigid anterior plating. However, our cohort size is similar to previously published work describing the clinical efficacy of this new class of cervical fusion implants. Future studies should include prospective analysis with more patients and comparative cohorts to truly define the clinical utility of these implants.

In conclusion, the low profile integrated device studied here improved cervical spine sagittal balance at the operated level and the correction was maintained at 1 year. Reported fusion rates with the new device are consistent with ACDF using anterior plating. In combination with patient-reported improvements in pain and a minimal rate of dysphagia, study findings support the use of integrated interbody spacers for use in one- and two-level ACDF procedures.

\section{References}

1. Kaiser MG, Haid RW, Jr., Subach BR, Barnes B, Rodts GE, Jr. Anterior cervical plating enhances arthrodesis after discectomy and fusion with cortical allograft. Neurosurgery. Feb 2002;50(2):229-236; discussion 236-228.

2. Xie JC, Hurlbert RJ. Discectomy versus discectomy with fusion versus discectomy with fusion and instrumentation: a prospective randomized study. $\mathrm{Neu}$ rosurgery. Jul 2007;61(1):107-116; discussion 116-107.

3. Daniels AH, Riew KD, Yoo JU, et al. Adverse events associated with anterior cervical spine surgery. J. Am. Acad. Orthop. Surg. Dec 2008;16(12):729-738.

4. Fountas KN, Kapsalaki EZ, Nikolakakos LG, et al. Anterior cervical discectomy and fusion associated complications. Spine (Phila Pa 1976). Oct 1 2007;32(21):2310-2317.

5. Lee MJ, Bazaz R, Furey CG, Yoo J. Influence of anterior cervical plate design on Dysphagia: a 2-year prospective longitudinal follow-up study. J Spinal Disord Tech. Oct 2005;18(5):406-409.

6. Sahjpaul RL. Esophageal perforation from anterior cervical screw migration. Surg. Neurol. Aug 2007;68(2):205-209; discussion 209-210.

7. Park JB, Cho YS, Riew KD. Development of 
adjacent-level ossification in patients with an anterior cervical plate. J. Bone Joint Surg. Am. Mar 2005;87(3):558-563.

8. Feiz-Erfan I, Harrigan M, Sonntag VK, Harrington TR. Effect of autologous platelet gel on early and late graft fusion in anterior cervical spine surgery. $J$ Neurosurg Spine. Nov 2007;7(5):496-502.

9. Goldberg G, Albert TJ, Vaccaro AR, Hilibrand AS, Anderson DG, Wharton N. Short-term comparison of cervical fusion with static and dynamic plating using computerized motion analysis. Spine (Phila Pa 1976). Jun 1 2007;32(13):E371-375.

10. Hacker RJ, Cauthen JC, Gilbert TJ, Griffith SL. A prospective randomized multicenter clinical evaluation of an anterior cervical fusion cage. Spine (Phila $P a$ 1976). Oct 15 2000;25(20):2646-2654; discussion 2655.

11. Mourning D, Reitman CA, Heggeness MH, Esses SI, Hipp JA. Initial intervertebral stability after anterior cervical discectomy and fusion with plating. Spine J. Nov-Dec 2007;7(6):643-646.

12. Stein MI, Nayak AN, Gaskins RB, 3rd, Cabezas AF, Santoni BG, Castellvi AE. Biomechanics of an integrated interbody device versus $\mathrm{ACDF}$ anterior locking plate in a single-level cervical spine fusion construct. Spine J. Jan 2014;14(1):128-136.

13. Nayak A, Stein MI, James C, et al. Biomechanical Analysis of An Interbody Cage with Three Integrated Cancellous Lag Screws In a Two-Level Cervical Spine Fusion Construct: An In-Vitro Study. Spine $J$ J Jun 162014.

14. Scholz M, Reyes PM, Schleicher P, et al. A new stand-alone cervical anterior interbody fusion device: biomechanical comparison with established anterior cervical fixation devices. Spine (Phila Pa 1976). Jan 15 2009;34(2):156-160.

15. Barbagallo GM, Romano D, Certo F, Milone P, Albanese V. Zero-P: a new zero-profile cage-plate device for single and multilevel ACDF. A single institution series with four years maximum follow-up and review of the literature on zero-profile devices. Eur. Spine J. Nov 2013;22 Suppl 6:S868-878.

16. Hofstetter CC, Kesavabhotla K, Boockvar JA. Zero-profile Anchored Spacer Reduces Rate of Dysphagia Compared to ACDF With Anterior Plating. $J$ Spinal Disord Tech. Nov 72013.

17. Li Y, Hao D, He B, Wang X, Yan L. The Effi- ciency of Zero-Profile Implant in Anterior Cervical Discectomy Fusion: A Prospective Controlled Longterm Follow-up Study. J Spinal Disord Tech. Oct 16 2013.

18. Njoku I, Jr., Alimi M, Leng LZ, et al. Anterior cervical discectomy and fusion with a zero-profile integrated plate and spacer device: a clinical and radiological study: Clinical article. J Neurosurg Spine. Oct 2014;21(4):529-537.

19. Riley LH, 3rd, Skolasky RL, Albert TJ, Vaccaro AR, Heller JG. Dysphagia after anterior cervical decompression and fusion: prevalence and risk factors from a longitudinal cohort study. Spine (Phila Pa 1976). Nov 15 2005;30(22):2564-2569.

20. Shin JS, Oh SH, Cho PG. Surgical Outcome of a Zero-profile Device Comparing with Stand-alone Cage and Anterior Cervical Plate with Iliac Bone Graft in the Anterior Cervical Discectomy and Fusion. Korean J Spine. Sep 2014;11(3):169-177. 21. Son DK, Son DW, Kim HS, Sung SK, Lee SW, Song GS. Comparative study of clinical and radiological outcomes of a zero-profile device concerning reduced postoperative Dysphagia after single level anterior cervical discectomy and fusion. J Korean $\mathrm{Neu}$ rosurg Soc. Aug 2014;56(2):103-107.

22. Yue WM, Brodner W, Highland TR. Persistent swallowing and voice problems after anterior cervical discectomy and fusion with allograft and plating: a 5to 11-year follow-up study. Eur. Spine J. Sep 2005;14(7):677-682.

23. Scholz M, Schnake KJ, Pingel A, Hoffmann R, Kandziora F. A new zero-profile implant for standalone anterior cervical interbody fusion. Clin Orthop Relat Res. Mar 2011;469(3):666-673.

24. Song KJ, Taghavi CE, Lee KB, Song JH, Eun JP. The efficacy of plate construct augmentation versus cage alone in anterior cervical fusion. Spine (Phila Pa 1976). Dec 15 2009;34(26):2886-2892.

25. Santoni BG, Alexander GE, 3rd, Nayak A, et al. Effects on inadvertent endplate fracture following lateral cage placement on range of motion and indirect spine decompression in lumbar spine fusion constructs: A cadaveric study. Int J Spine Surg. 2013;7:e101-108.

\section{Disclosures}

Antonio Castellvi was a consultant for Centinel. The 
other authors declare no relevant financial disclosures.

\section{Corresponding Author}

Brandon G. Santoni, Ph.D., Foundation for Orthopaedic Research \& Education (FORE), $13020 \mathrm{~N}$. Telecom Parkway, Tampa, FL 33637. bsan- toni@foreonline.org.

Published 17 July 2015.

This manuscript is generously published free of charge by ISASS, the International Society for the Advancement of Spine Surgery. Copyright $\odot 2015$ ISASS. To see more or order reprints or permissions, see http://ijssurgery.com. 